\title{
EL SISTEMA EDUCATIVO COMO MURALLA. ¿DIRECTORES GENDARMES?
}

\author{
Analia Umpierrez (Universidad Nacional del Centro \\ de la Provincia de Buenos Aires)* \\ aumpierr@soc.unicen.edu.ar
}

Recibido: 18/07/2012 Aceptado: 10/09/2012

\section{Resumen}

La obligatoriedad del nivel secundario a partir de la sanción de la ley 26.206 se constituye en una oportunidad democratizadora a la vez que en un desafío para las instituciones educativas. Una revisión histórica que enlaza imaginarios sociales e imágenes superpuestas de una ciudad de rango intermedio de la Provincia de Buenos Aires, permite mirar los "adentros" y "afueras" en una sociedad compleja. Así, se advierten políticas estatales que profundizan la segregación y el giro autoritario a partir de diferentes aparatos del estado, entre ellos, la escuela.

\section{Palabras clave}

Obligatoriedad escolar - Escuela secundaria - Imaginarios sociales - Inclusión/ exclusión - Gubernamentalidad.

\begin{abstract}
The obligation upon secondary level from the penalty of 26,206 law constitutes a democratizing opportunity while a challenge for educational institutions. A historical review linking social images and overlays of a mid-level city, lets look at the "insides" and "outside" in a complex society. Thus, state policies are noted in the Province of Buenos Aires that deepen segregation and "rightward" from various agencies of the State, including school.
\end{abstract}

* Magister en Educación con mención en Ciencias Sociales (UNICEN). Profesora Adjunta Ordinaria de la Facultad de Ciencias Sociales (FACSO), Universidad Nacional del Centro de la Provincia de Buenos Aires (UNICEN). Investigadora del grupo Proincomsci (Programa de Investigaciones Comunicacionales y Socio-culturales de la Ciudad Intermedia) FACSO-UNICEN. Directora del Programa "Educación en contextos de Encierro" FACSOUNICEN. 


\section{Key words}

Obligatory-High School-Social imaginary-Inclusion/exclusion-Governmentality.

\section{Introducción}

La obligatoriedad y masividad del nivel Secundario se instituyó en la Argentina en el año 2006(1). Es sabido que la escuela secundaria se constituye en un dispositivo en el que se localiza simultáneamente el mandato de inclusión prescripto desde el nivel central del Sistema Educativo a la vez que opera como "clasificación" social (2). Aquí se propone analizar algunos aspectos identificados en dos escuelas secundarias de la localidad de Olavarría (3), Provincia de Buenos Aires, seleccionadas a los fines de esta presentación. Se privilegian las articulaciones que se dan entre las historias fundacionales, los mandatos, y los imaginarios sociales. Las imágenes de "ciudades superpuestas" (Gravano, 2005) como hipótesis (4) permite identificar enlaces entre los procesos sociohistóricos de estas gestaciones y el presente.

Asimismo, se propone identificar algunos "conectores" que ligan algunas políticas educativas con las políticas de seguridad de la Provincia de Buenos Aires -en los ámbitos de la policía y penitenciaría-, ya que se advierten como parte de un mismo dispositivo social de control propio del "formato" asumido por el estado provincial. La conformación y sostén de un modelo y tipo de gubernamentalidad [5] (Foucault, 1978) demanda aceptaciones y sometimientos. Las líneas de conducción del gobierno provincial se advierte en prácticas específicas. En algunas escuelas secundarias se observa la designación de directores provenientes del área de la Educación Física que estarían en consonancia con la construcción social y sostén de "fronteras", límites imaginarios que clasifican y seleccionan a la población. Esto se asocia a los imaginarios y las imágenes residuales de "ciudades superpuestas". Olavarría, como tantas otras surge como fortín, en la conquista del "desierto". Esta es una paradoja que se sostiene y se dirime aún hoy: las escuelas "de bordes" se constituyen en puestos de avanzada sobre el "desierto", que como entonces niegan la existencia de sujetos portadores de culturas, historias, intereses, necesidades propias. La tarea de quienes se constituyen en responsables de la conducción podría aproximarse entonces al papel que los gendarmes (6) supieron tener en la línea de frontera que se iba trazando en la lucha con los habitantes originarios del territorio de la provincia y del país en su conjunto.

Se acude en este trabajo a documentación de archivo, registros de observación y entrevistas en campo de los últimos años y especialmente del año 2012. La perspectiva metodológica privilegia la voz y los sentidos asignados por los actores por lo que centralmente es de corte cualitativa, sostenida por enfoques socio-antropológicos y de análisis institucional. 


\section{La Gendarmería volante se retira. Un predio para la Escuela de Lechería.}

Una escuela centenaria en la ciudad es la Escuela de Agricultura $N^{0} 1$. Su historia permite recuperar los sentidos asignados, los mandatos que recibió componiendo el trazado de espacios, destinatarios y destinos de la educación secundaria y su articulación con la vida política, económica y cultural de la ciudad. La escuela nace en 1911 (7) como "Escuela práctica de lechería" y recién en 1970 se convertiría en escuela de nivel secundario, otorgando el título de "Agrónomo Nacional". Se la ubica en el edificio de lo que fuera un regimiento de frontera, la Gendarmería Volante (8), en un predio muy alejado de lo que en ese entonces era la planta urbana (aún es hoy un predio muy alejado de la ciudad, en zona de quintas de fin de semana). Las señales de identidad que se pueden reconstruir a partir de ubicar en ese lugar -un cuartel de gendarmería- dan cuenta de una frontera que se expande y gana terreno al indio, que consolida a la ciudad como tal, en la que se promueve la enseñanza de la explotación de la tierra y el ganado desde una formación técnica.

Los promotores de esta fundación son los ciudadanos ilustres, las fuerzas económicas propietarios del capital -fábricas, bancos (9) y miembros de sociedades económicas- que conforman el movimiento cívico que desarrolla el comercio, la industria, la explotación del campo y la cultura local. Son los mismos actores que intervienen conformando las instituciones de la naciente ciudad. En este proceso la educación tiene un papel preponderante.

\section{Los inicios del Colegio Nacional N$^{\circ} 2$ "El Fortín de las puntas del Tapalquén"}

Otra escuela seleccionada en este rápido recorrido permite dar cuenta de fundaciones y visiones de ciudad. Es la del segundo Colegio Nacional de la localidad. Los siguientes son fragmentos de una entrevista a la directora (10) que asume en términos de Fernández (1999) la gesta fundacional

(...) hubo gente dentro y fuera del barrio que pensaron que ahí hacía falta un colegio nacional porque hacía más de 35 años que no se fundaba ninguno y aquel era un barrio como de 40.000 personas o más, se estaban construyendo barrios y todo del otro lado de la vía. En todos los pueblos, toda la vida estuvo "del otro lado de la vía", que era una cosa medio intocable para la gente del centro, la gente del centro se quedaba en el centro. Bueno, entonces cuando se creó esto, que era una idea, era lo que ahora se puede llamar como "ciencia ficción", porque no había lugar, no se sabía dónde iba a estar, no se sabía nada. Se consiguió un chalet que tenía dos habitaciones y una galería y eso fue el comienzo de todo" (L. G. 1era directora). 
Se refiere al Barrio "El Fortín", conocido o mencionado en esa clave, "detrás de las vías", divisoria del casco urbano. Este límite "natural" señala aspectos conducentes a "comprender" cómo son o se imaginan las cosas respecto de "los de ese lado". Queda claro que en esta trama la educación es el foco en el que se anclaran los análisis. Se relevan desde la voz de la directora aspectos de esta gesta fundacional:

Tengo muchísimas anécdotas acerca de ese detrás de las vías. Una vez fui a pedir dinero a una persona importante y me dijo: - Qué les vas a dar, para que te voy a dar plata para esos negros que viven atrás de la vía, son todos peronistas, me dijo". (Comunicación personal, L. G. 1era directora).

Así, la construcción de unos y otros, la estigmatización social sobre sectores de la comunidad construyen cercos imaginarios, en los que "las vías" se convierten en el referente material de la "divisoria" entre civilización y barbarie, si se quiere pensar en términos ilustrados y fundantes del sistema educativo (Tamarit, 1993).

Pensar en la creación de un Colegio Nacional, localizado en esa zona de la ciudad daba cuenta de un acontecimiento impensado, especialmente cuando se identifican "quienes" serían los destinatarios de esa escuela, que tendría en principio una distinción respecto de las creaciones más recientes, desde la órbita provincial: era un colegio Nacional y como tal se presuponía de mayor nivel. Así la por entonces Directora de Educación de la Municipalidad (11), que tuvo un protagonismo político importante en la concreción de la creación, expresaba en una entrevista:

(...) vi en ese entonces que las escuelas secundarias de provincia tenían un nivel que no tenía nada que ver con las escuelas secundarias digamos públicas como la Normal, el Comercial, el Nacional, por su trayectoria y demás, y eran tomadas como las escuelas pobres del sistema" (Comunicación personal AT. Mayo 2011).

Con esta intención, pero en esa zona estigmatizada de la ciudad, se instalaba este colegio: destinado a seguir la tradición y la distinción de ser "Nacional" en un barrio estigmatizado: "detrás de las vías" y "peronista".

Respecto de la imposición del nombre, relata la primera directora:

Dos nombres surgieron de reuniones entre padres, profesores, alumnos y vecinos: "Manuel Belgrano" y "Fortín de las Puntas del Tapalquén" (...) el primer fortín que se hizo acá se llamaba el Fortín de las Puntas del Tapalquén. (...) en una reunión a la que asistió todo el barrio para votar, fueron 98 votos para el Fortín, 58 para el Belgrano y 4 votos impugnados. El 25 de noviembre día en que se festeja la fundación de Olavarría se impuso el nombre que aunque 
largo refleja la fundamentación. El Fortín era el lugar al cual iba la tropa y los colonos a buscar refugio, el lugar donde primaba la cultura en contraposición con la dureza del desierto, el colegio fue en ese momento el lugar de cultura en el barrio que detrás de las vías clamaba por él (L.G. 1era directora).

El Nacional N² 2 se constituía así en un ámbito civilizatorio, de "avanzada" como lo fue el fortín respecto de la conquista y exterminio de los pueblos originarios; avanzada que se presenta en el relato oficial como "desierto". Muchos militares que en esos tiempos buscaron respetar y acordar con los pueblos dueños de las tierras fueron desacreditados, perdieron rangos y espacios. Esta directora, quien fue capaz de movilizar y trabajar con la comunidad, de igual a igual, más allá de este imaginario residual ilustrado muy pregnante, corrió igual suerte. Desgastada por la falta de respuestas oficiales y la imposición de arbitrariedades, a la par que se pone en vigencia la ley de transferencias de escuelas, desemboca en una licencia y posterior retiro de la docencia. La gesta se logra y en este mandato (12) se develan sentidos encontrados y contradictorios: escuela de excelencia para la "barbarie"; civilizar y conquistar desde el puesto de frontera al "bárbaro".

Desde el otro lado de la ciudad las voces de los vecinos decían "eso no va a durar... y mirá, ya pasaron más de 20 años (sonrisa)" comenta la primer secretaria de la escuela (13). La doble cara del mandato, educación de excelencia/civilizar es parte de las claves de análisis sobre la concreción y trayectoria de esta escuela. A más de veinte años de la inauguración de la escuela, se actualiza la imagen de "desierto" y de la escuela "como frontera". Dice una profesora de la Escuela Media 7 (14):

"a veces digo, no sé si me está gustando tanto vivir en Olavarría porque uno por ahí quiere estar desconectado de ciertas cosas $(. .$. en estos tres años he escuchado de mis alumnos cosas que... y que no es que yo viva en una burbuja... pero cosas que tienen que ver con que Olavarría creció un montón como ciudad...escucharlos contando de las veces que han estado en la comisaría...(...) yo vivo a cuatro cuadras de la comisaría segunda y pasaba a cuatro cuadras de mi casa, y contaban cuando te ponen contra el paredón del Club El Fortín... claro...en algún punto lo entendés, que nada los motive y descrean de todo, porque viven realidades totalmente distintas a la tuya...qué le vas a decir, que leer un texto les va a cambiar la vida..., de última uno no pierde la esperanza y trata de hacer lo posible pero...yo creo que eso es la docencia, es tratar de pararte ahí, aunque nadie tenga ganas de escucharte, pero por ahí por hacerlo conscientemente y con compromiso y no olvidar que están enfrente, por ahí uno te va a escuchar" (Comunicación personal, A.R marzo 2008) [15]. 
Permítase a esta altura acudir a una cita extensa pero central por su aporte para el análisis que se está pretendiendo hacer en este trabajo. Fernández (1999:5) al abordar la relevancia de la gesta fundacional y la historia de las instituciones educativas nos advierte y señala el modo en que esta contradicción fundante se actualiza y mantiene viva una paradoja:

La creación de una escuela es símbolo de potencia y progreso y este significado se "enraiza" en las tradiciones que tienen su origen en las ideas libertarias del movimiento de emancipación.

En el proyecto de los fundadores de la nacionalidad, la escuela aparecía como una avanzada heroica. Estaba ligada y se "hacía" sobre los jirones de una lucha cruenta de liberación respecto de una metrópoli colonial en el nombre de quien -valga la paradoja- se había iniciado la guerra.

En el siglo pasado la fundación de escuelas se enlazó a la utopía de un destino nacional de grandeza y al desafío de lograr que un cúmulo de nacionalidades se amalgamara en una identidad única. Se hablaba ya de la "madre patria" y con sus hijos (todos los inmigrantes) avanzaba la escuela sobre los restos de las culturas nativas. Las mismas a las que deberíamos en buena parte la conformación de los ejércitos de la emancipación. Y vale de nuevo la paradoja.

El avance de la escuela se hizo sobre la negación de estos desgarramientos. Existió una historia oficial que permitió justificar hechos y aliviar culpas pero no pudo evitar el sobreesfuerzo de crecer soportando en su mismo interior una profunda contradicción.

Pueden reconocerse así, en el plano de lo local, elementos que entraman con los debates y decisiones que se están llevando a cabo en otros ámbitos [16] (Souto, 2000) y que pueden identificarse, analizarse y comprenderse en la medida en que se advierta que trascienden lo local enlazándose justamente en los diferentes ámbitos más distantes y ajenos y que dan sentido a los procesos sociales. Elías (1999:94) expresa esta relación como un proceso de entramado que va conformando la vida social,

(...) está claro lo que se quiere decir cuando se refiere esta relación como un proceso de entramado: sólo es posible entender y explicar la sucesión de los actos de ambas partes en su mutua interdependencia. Si se considerase la sucesión de los actos de cada parte en sí misma, aparecería como carente de sentido.

Este proceso de entramado da cuenta de relaciones, de configuraciones de interdependencia, de "la relativa opacidad del juego en que se practican sus jugadas, y de la posibilidad de reducir esa ignorancia mediante la investigación sistemática" (Elías, ibidem: 102). 
Así, la articulación entre lo que se mira y analiza en las instituciones particulares y la lectura social de la ciudad en un período socio-histórico específico se entraman con la lectura social más amplia. Poner la mirada en lo local nos permite advertir cómo se construyen y sostienen imágenes urbanas compartidas, superpuestas, memorias activas de los diferentes proyectos y materializaciones de ciudad que de algún modo advierten las dinámicas, los lugares sociales asignados/asumidos, los prejuicios y estigmatizaciones que constituyen el cotidiano de los habitantes, vivido y actuado la mayor parte de las veces de modo "natural". Así, las sucesivas imágenes de ciudades que son parte de la lectura de imaginarios de la ciudad de Olavarría caracterizadas por Gravano (2005) que se van superponiendo son: - "de frontera": "una imagen vigorosa mediante la que se construye la identidad de la ciudad posterior y que se refleja en el imaginario tanto erudito local como oficial: su carácter épicofronterizo, de los blancos contra los indios" (Gravano, 2005:37). El resaltado es nuestro); -*"de tribalismos blancos": "una imagen de ciudad europea y caucasoide, una de cuyas variantes sería la "ciudad gringa", [italiana] (...) representación de crisol de razas, traducido a la imagen de crisol social" (...) "lo que se busca es la esterilización del conflicto, tras el mito de la integración" (Gravano, 2005:40/43); *"del cemento": "se corresponde con el proceso de industrialización y modernización de la ciudad de Olavarría [1920/1940] en el contexto nacional y con la profundización de la idea de "punta de lanza civilizatoria» que es la forma que adquiere el desarrollo capitalista en un momento de afianzamiento expansivo del asentamiento urbano, consolidada ya la situación de las tribus blancas dentro de la frontera" Gravano, 2005:45); *"del trabajo", "identidad definida, mitologizada en su imaginario social durante una época expansiva del capital y del modelo socioeconómico desarrollista" (Gravano 2005:19). Finalmente el autor nomina la última imagen como * ¿ del ex-trabajo?" a modo de interrogante ya que en el momento de la investigación se está viviendo la profunda crisis económica de alto impacto social y cultural en la que se está redefiniendo el imaginario social local. En un trabajo anterior de la autora (Aurora, 2009:72) se deja planteada la hipótesis de que "la crisis del imaginario local construido como emblema de "cuidad del trabajo», deja como interrogante abierto si no estará mutando, deslizándose Olavarría hacia la "Ciudad de la seguridad/ inseguridad»" a partir de la identificación de diferentes ofertas formativas (penitenciaria, policía) y su vinculación con el avance creciente de la "industria de la seguridad", como lo presenta Wacquant (2008) vinculada a puestos de trabajo en relación al Estado, que sostienen un modelo de empleo residual y un imaginario vinculado a la continuidad de un modelo de estado "social".

Estas sucesivas imágenes de ciudades superpuestas se entraman con la conformación y las tensiones que se reconocen en el nivel educativo secundario de la ciudad. Se pretende por tanto, construir puntos de articulación entre las 
posiciones y toma de decisiones de los actores locales con las tramas provincial, nacional e internacional que se estaban viviendo en los diferentes períodos. Las tensiones, las tomas de posición, las elecciones se juegan y dirimen dando cuenta de las fuerzas de juego [17] (Elias, 1999:88).

A modo de síntesis de lo hasta aquí planteado, podría decirse que:

- Relevar los antecedentes de la escuela de Agricultura $N^{0} 1$ permite ver cómo se avanza en el terreno ganado al indio y se da el pasaje de ciudad de frontera a "ciudad blanca". La ciudad de frontera materializa con esta creación un límite que muestra su avance y consolidación: allí donde había estado un grupo armado de gendarmes que custodiaban los límites de la ciudad, el terreno "conquistado" ahora se sostiene con la educación para la colonización a través de la tierra y la explotación ganadera.

- Revisar las representaciones respecto de la educación en la fundación de una escuela secundaria en un barrio "detrás de las vías", en la década de los 90, un siglo después de la Escuela de Lechería, actualiza un imaginario social vinculado al papel civilizatorio de la escuela: colocar en "la frontera" avanzadas contra la ignorancia y la barbarie.

Esta mirada hacia el pasado, el modo en que se idea y concreta la conformación del sistema educativo en una ciudad de la provincia de Buenos Aires, que aunque en principio particular, permite conformar una mirada sobre una provincia que fue corriendo la línea de frontera y disputando al indio sus tierras y la riqueza en diferentes localidades que vivieron procesos similares, permite enlazar con el presente y las "fronteras" en las que se disputa el orden, la gobernabilidad de la provincia.

- Establecer articulaciones entre estos procesos que se advierten en el sistema educativo y los imaginarios sociales, los proyectos de ciudad que se juegan entrelazados, permite dar un nivel de profundidad al análisis hacia la comprensión de tramas no advertidas desde los discursos y registros oficiales en los que la creación de establecimientos educativos se presentan en un sentido positivo exclusivamente y no se advierte su dialéctica social.

\section{Un paso más: las tensiones de época y las "fronteras"}

En estos (nuestros) tiempos, las fronteras continúan ahí. Hay territorios "peligrosos" y "zonas liberadas" que amenazan y anuncian el límite de la civilización. Detrás de estas fronteras están localizados amplios sectores de la población tamizada a partir de las categorías clase, raza, género y religión (Apple, 1996). En esta selección los y las jóvenes, especialmente pobres, son destinatarios de políticas de "inclusión". Parecería que no son parte y hay que incluirlos socialmente, que la sociedad está en una parte y ellos están "más allá".

En una entrevista realizada a la Inspectora Jefa Distrital (18) de la ciudad de Olavarría, en la que se le interrogaba acerca de "las posibles causas por las que emergen episodios de violencia escolar", la inspectora consideró: «no 
es un tema que hay que tomarlo como que los pibes son violentos, de ninguna manera. Es la multiplicidad de situaciones la que hace que se generen algunas situaciones de violencia»; opinó y reconoció que los docentes «venimos de una historia donde estábamos preparados para los que podían acceder al sistema y los que quedaban fuera, y hoy tienen que estar todos» concluyó" (19).

Desde el sentido común (20) siempre circuló que la escuela secundaria era para unos y el trabajo para otros. En los sucesivos y largos años en que se fue generando y profundizando el avance del estado neoliberal, el destino de miles fue el desempleo, la miseria, el no futuro (Bauman,1999; Tenti Fanfani 2008). La Inspectora Jefa Distrital repite una frase que desde el sentido común señala la tensión entre el imperativo de la ley y la fuerte creencia de que la escuela secundaria es para "unos" y con ello se identifica la (in)capacidad de la escuela y los docentes para recibir a "quienes podían acceder al sistema" a sabiendas que "otros" no llegarían: "los que quedaban fuera". Para recibir a esos la escuela y los docentes no estarían preparados.

Desde la sanción de la ley "todos y todas a la escuela" es el lema que impera desde el mandato oficial. ¿Cómo manejar esta masa de sujetos que "no tienen las condiciones" para acceder a la escuela secundaria? Desde sus modales, vestimenta, gustos, lenguaje, creencias, conflictos con la ley -una construcción social estigmatizada y estigmatizante de delincuentes, drogadictos, malhechores, "ineducables" (Tamarit,1993)- dan cuenta de marcas de clase, etnia, género y religión que confrontan con las tradiciones instaladas respecto de quienes son los destinatarios "exitosos" y "los que quedan afuera" de las escuelas del nivel, unos jóvenes que están "enfrente" -como expresaba la profesora- y no se sabe bien cómo llegar.

En el conjunto social, asimismo, se convierten estos últimos en focos de intervención y destinatarios de políticas públicas (planes de inclusión educativa; empleo joven; callejeadas, entre otros) para "retirar a los jóvenes de la calle", "inducirlos al mundo del trabajo", sacarlos del riesgo del consumo de drogas.

En este conjunto de políticas se le demanda al sistema educativo que de ingreso, retenga, promueva y gradúe a estos jóvenes. Este es el punto de clivaje que se quiere analizar. Los modos en que se definen y llevan adelante prácticas conducentes al logro de estos objetivos.

Una estrategia que se advierte en la política del gobierno justicialista de Daniel Scioli es la recurrencia de una conformación de instituciones "gendarmes". Instituciones que más que promover la participación plena, la construcción de lazos desde el respeto y la garantía de derechos, tomarían como base un modelo de dominación por la coerción y "la mano dura", aunque se prescribe la retención y las búsquedas de sostén de los y las jóvenes como discurso oficial. En este reconocimiento se incluyen los modos en que actúan y se dejan actuar a los aparatos que tiene la legitimidad por ser fuerzas de seguridad del Estado: la policía y la penitenciaria, y las instituciones que representan los aparatos 
ideológicos del estado (Althusser, 1988), especialmente focalizando la escuela secundaria, en donde prácticas manipuladoras hacen de la participación de los jóvenes un "como si" (21). Así, Calvete y Vales (2011:87) señalan:

El espacio escolar puede adquirir una importancia central en el marco del fortalecimiento de la condición ciudadana de los jóvenes, en la medida en que amerite los espacios de diálogo y escucha, de organización, debate y participación en la toma de decisiones por parte de los jóvenes, cuando las irrupciones de los mismos no sean sancionadas y se comprendan los nuevos modos de hacer política por parte de los estudiantes. Cuando todo ello se traslade a las prácticas concretas se podrá hablar quizás de una democratización institucional.

Asimismo, cabe recuperar aquí que es en las escuelas singulares en las que

"el trabajo docente se construye en las formas cotidianas de la micropolítica institucional, en el entramado de las condiciones materiales y las relaciones sociales. Por eso, cada escuela singular es el espacio en el que lo homogéneo toma cuerpo a partir de formas heterogéneas de existencia institucional (Ezpeleta, 1989). Se trata de procesos de negociación en la red de relaciones (internas y externas) en las que la escuela se inscribe. Es allí donde se abre el espacio de las estrategias individuales e institucionales" (Birgin, ibidem1997).

Los sujetos, como actores de su tiempo histórico, tienen posibilidades y límites en sus actuaciones. En este sentido, la perspectiva elegida para analizar la relación que se construye entre los diferentes actores -docentes, padres, estudiantes, autoridades- y la escuela se reconoce como relacional y posicional, contextuada socio-históricamente. Los entramados de interrelaciones que conforman la cotidianeidad de las organizaciones han de poder mirarse desde lo uno y lo múltiple, buscando identificar las fuerzas de juego que construyen la tensión del entramado. Interpelar a los actores pero sin dejar de ver en este foco, la complejidad de su actuación y relaciones en la trama, en que se implican y construyen. El juego de poder y de fuerzas está regulado por las características del entramado de las relaciones interdependientes de individuos (Elías, 1999: 94).

La conformación y sostén de un modelo y tipo de gubernamentalidad (Rose, 2007, p. 113) [22] demanda ajustar la mirada respecto de aceptaciones y sometimientos. Aquí se busca revisar los "conectores" que ligan estas políticas públicas -conformar de un tipo de sujeto que acepte y comparta esta ideología-, advirtiéndose una "derechización" que parecería concretarse en la selección de cierto perfil de directores que aportaría a este modelo de gubernamentalidad. El papel que juegan los actores situados es clave en esta mirada, ya que son 
las decisiones que se materializan en el plano local las que van conformando movimientos que dan cuenta de la dinámica social, tal como plantea Elías (1999) al referirse a las interdependencias de las configuraciones.

\section{Las escuelas secundarias de "borde"}

Comienza a llamar la atención a partir del gobierno de Scioli la elección y designación de directores de escuelas secundarias, mayoritariamente "de bordes", provenientes del campo de la Educación Física. Sorprende porque no era tradición que estos docentes ocuparan cargos de gestión, a excepción de los de la propia rama (como es el caso de los Centros de Educación Física). La misma Jefatura Regional de Educación (Región 25) es ocupada por una Profesora de Educación Física. Este cargo tiene una impronta netamente de "confianza política" ya que se designa a propuesta de la Jefatura Regional de Educación.

Ahora bien, ¿por qué a la hora de seleccionar y calificar en ámbitos de concursos, los profesores de educación física se colocan en primeros puestos? Una de las razones legales se ubica en una resolución del año 2005 (23) que habilita a estos profesores -entre otros- a presentarse a concursos directivos si son titulares en el nivel que aspiran. Asimismo, se les reconocen antecedentes (como por ejemplo participar en la conducción deportiva, eventos, etc.) que les otorgan un puntaje, antecedentes que docentes de otras modalidades no cuentan. Así, es incuestionable la legitimidad de la designación de cargos ya que se alcanza por concursos.

Se ponen en juego también las tensiones hegemónicas de género. La educación física es una de las modalidades que sigue teniendo gran presencia de hombres que estudian y ejercen la docencia. Es sabido que la docencia es una carrera que se ha ido convirtiendo en un campo laboral de mujeres -la construcción de la feminilidad asociada a la enseñanza como una "ocupación de mujeres", tal como plantea Morgade (1992); y las similitudes con el magisterio para el profesorado a partir de la masividad del nivel (Birgin, 1997) [24]. Esta área, desde sus inicios se la privilegió para varones y lentamente fue incorporándose a las mujeres. Por otro lado, puede reconocerse que los cargos de gestión y la carrera por el escalafón es más rápida y probable a ser conquistada por hombres: a pesar de ser muy inferior en número los docentes varones, son muchos los que ocupan cargos directivos y de inspectores, así como cargos políticos en la gestión del sistema educativo provincial (este último aspecto se está modificando en los últimos años).

Por otro lado, y esta arista se considera relevante aquí, se advierte desde la historia de la educación física en la Argentina, que la incorporación de la disciplina a la escolaridad primaria tuvo fuertes raíces militaristas que buscaban la formación de los niños fortaleciendo la masculinidad, especialmente a través de la disciplina militar, en la perspectivas sostenidas por el 
Dr. Honorio Leguizamón y el Dr. Pourteau a finales del siglo XIX (Aisenstein y Scharagrodsky, 2006). Otra vertiente fue la higienista que asocia la práctica deportiva a la salud destacándose la producción del Dr. Enrique Romero Brest a inicios del SXX (Agüero, Iglesias, del Valle Millanino, 2009). Así, pueden advertirse en la historia de la enseñanza y el currículum de la disciplina en Argentina diferentes vertientes (25). En estas tensiones la educación física se incorpora y va transformándose curricularmente pero la impronta de moldeamiento del cuerpo, la disciplina, la masculinidad y el nacionalismo están vigentes: "obsesión por el disciplinamiento, obsesión por cierto tipo de virilidad y obsesión por determinada manera de ser patriota" (Aisenstein y Scharagrodsky,et.al 2006, p. 117).

Revisando las "marcas" de la disciplina en vinculación con el gobierno de la población (Caruso y Dussel, 1999), pueden identificarse en la historia de la educación física de la Provincia de Buenos Aires, raíces militaristas y fascistas. En la década de 1930 se llevan adelante una serie de reformas muy importantes en la Provincia de Buenos Aires. No obstante merece recordar que este periodo es conocido como la "década infame" (1930 a 1943) y del "fraude patriótico". La creación de la Dirección de Educación Física se produce en el año 1936 durante el gobierno del Dr. Manuel Fresco y su ministro de educación Dr. Roberto Noble, época en la que se debate y busca en el ámbito pedagógico quitar de escena los avances de la Escuela Nueva, y el normalismo recupera terreno (Carli, 2003). Un gobierno que pretende ser innovador y progresista pero con fuertes marcas conservadoras, coloca en la educación un anclaje clave para sus propósitos. La lucha internacional y la "amenaza del comunismo" exacerban la decisión de construir consensos y adhesiones a las líneas más duras del nacionalismo que se reflejan en el fascismo. En este contexto se coloca el foco en esta disciplina.

Esta impronta en la Dirección y en los ámbitos de formación es muy fuerte aún. Si se acude a la historia del Instituto de Educación Física de Olavarría, se identifica en sus orígenes una marca militar y católica (26) importante desde quienes llevan adelante la gesta de fundación. Su propuesta y concreción se da entre los años 1970/ 71, época gobernada "de facto", gesta que sus fundadores denominan "época dorada" (Herrera, 1992). No es el propósito aquí realizar un análisis institucional del Instituto, pero vale la referencia a rituales de iniciación que se sostienen hasta el presente, aunque de otro modo, como es la fiesta de la "I": Ios ingresantes reciben el distintivo -una letra I mayúscula en paño que portarán prendida a sus uniformes durante toda la formación docente- en un acto de "bautismo" al que los ingresa un "padrino" (un estudiante avanzado) [27].

Así, un docente y director en ejercicio rememora:

"el bautismo,...la fiesta de la I.....Ahí las sensaciones fueron medias mezcladas, tiene que ver con una tradición aunque no siempre 
fue así, se pasaban de los límites. ... lo de la jerarquía lo de tener que pagar derecho de piso, lo de "sos una rata" mezcladas con las actividades que tenían que ver con el aspecto recreativo de integración que, eran manejadas solo por alumnos de tercer año, no había profesores eso, eso estaba bueno". (Registro en Sosa, 2007, p 17).

Asimismo, Sosa (2007) [28] advierte en su análisis respecto de la construcción identitaria del profesor de educación física durante la formación de grado, aspectos que darían cuenta de que se ha opacado la dimensión política durante esa formación y posteriormente en el ejercicio de la tarea profesional. Esta "despolitización" de la práctica coloca a los profesores en un espacio para la acción en muchos casos de "lectura ingenua del mundo" en términos de Freire (1990).

La decisión de habilitarlos a concursar cargos directivos, la bonificación en esa instancia con puntos obtenidos por su trayectoria especialmente deportiva (encuentros, torneos, etc.) que otros aspirantes no cuentan, dan oportunidad y cierta ventaja a los profesores de educación física. La decisión política de abrir este camino se vincula a nuestro entender, con determinadas visiones y decisiones respecto de la gestión política y la gubernamentalidad de la provincia y las "marcas" de origen que esta disciplina trae.

No obstante, los actores tienen sin duda capacidades para hacer otra cosa, en la medida que hagan una revisión de los sentidos asignados a la enseñanza y la educación y puedan advertir la dimensión política de su práctica.

\section{Policías y penitenciarios en la mira}

En la provincia de Buenos Aires se vienen registrando una serie de denuncias que ponen en la mira procedimientos y prácticas que se dan tanto en el ámbito de la estructura policial como penitenciaria. Se toman como referencias el documento publicado por el Centro de Estudios Legales y Sociales (CELS) (2012) y las notas periodísticas aparecidas entre abril y junio de 2012 en el diario capitalino Página/12. Pueden leerse en el informe publicado por el CELS, en el capítulo dedicado a la provincia, referencias como las que siguen:

La provincia de Buenos Aires sostuvo durante los últimos cuatro años, políticas de delegación de la seguridad en la propia Policía Bonaerense. La situación actual de la provincia es la consecuencia de esa sostenida decisión política. A través de hechos conmocionantes pueden verse complejas tramas en las que se superponen la ineficiencia para investigar, la corrupción, la connivencia con redes delictivas y la violencia policial (CELS, 2012, p. 144). 
Más aún, existen políticas públicas de seguridad que se afirman sobre concepciones que reproducen y realimentan la estigmatización de estos sectores, como los operativos de saturación, llevados adelante frecuentemente en villas y asentamientos del conurbano, identificándolos con las amenazas a las que hay que combatir. Aun cuando los abordajes territoriales intensificados también son una opción impulsada por el gobierno nacional, su racionalidad y diseño son diferentes. Los allanamientos masivos de la provincia son operativos disruptivos, asociados generalmente a un caso que causa conmoción pública y para el que se activan respuestas rápidas, violentas y en los que no se reconoce a los vecinos afectados como interlocutores del gobierno y beneficiarios de los servicios de seguridad sino como objetos bajo requisa e investigación.

El modelo delegativo asumido por el gobierno provincial desarmó gran parte de los avances de la reforma policial bonaerense (2004-2007) [29]. En los primeros años de esta gestión (2007-2011) se impulsaron reformas normativas para desarmar el andamiaje jurídico: se abandonó la dirección civil, se desarticuló la política de participación ciudadana y de prevención comunitaria de la violencia y las herramientas de gestión que permitían el monitoreo de los fenómenos de inseguridad y el control del trabajo policial. El gobierno provincial progresivamente dio marcha atrás con los cambios que se habían realizado en la estructura de la policía y terminó optando en la práctica por un esquema de autogobierno, expresado en la decisión institucional de fusionar los ministerios de Seguridad y de Justicia y de elevar el cargo de Jefe de la Policía al rango de Subsecretario (CELS, 2012, p. 145-146).

Así, a lo largo del informe se van presentando y analizando los modos en que el poder ejecutivo ha habilitado y facilitado que las fuerzas policiales no solo resulten en situaciones de inoperancia e inacción sino que a partir de casos muy resonantes se advierta el "autogobierno" de las fuerzas habilitado por el propio gobernador, señalándose además "la incapacidad del Ejecutivo provincial para investigar el rol deficiente de la justicia, que resulta incapaz de abrir fisuras en el escenario de autonomía policial de la provincia" (CELS, 2012, p. 153).

Por otro lado y desde las acciones llevadas en las penitenciarias de la Provincia, el presidente de la comisión de Derechos Humanos de la Cámara de Diputados Remo Carlotto reconoce que:

la política que se lleva adelante en la situación de la seguridad y la de las personas privadas de su libertad en la provincia es realmente violatoria de los derechos humanos. Ha quedado muy claro en la visita que realizó el vicegobernador (Gabriel) Mariotto junto a organismos de DD.HH. a unidades carcelarias, donde las condiciones de detención son degradantes (30). 
En las cárceles se denuncia no sólo falta de alimentos, salud, condiciones inhumanas de los edificios e instalaciones, presencia de roedores, cucarachas, falta de agua, sino que ese escenario se ve agravado por las torturas y asesinatos de manos de penitenciarios o bien encargos de asesinato de presos sobre presos. Estas denuncias llegaron a la vice-gobernación (31)

la Comisión Interamericana de Derechos Humanos concedió una medida cautelar solicitada por el CELS y la Comisión Provincial por la Memoria luego del asesinato a golpes del interno Patricio Barros Cisneros, y responsabilizó al Estado Nacional por la integridad y la vida de las personas privadas de su libertad en el Complejo Conurbano Norte". (...) "Los homicidios en unidades penitenciarias provinciales aumentaron casi un 20 por ciento durante el último año. Estas muertes vienen acompañadas por una persistente situación de hacinamiento, torturas, malos tratos y privaciones estructurales de derechos. La violencia extrema en los lugares de encierro se explica, en general, por lo que hace o deja de hacer el SPB, que aparece como intocable. La negación política de la situación alimenta las respuestas represivas y ha reafirmado la autonomía con la que el SPB se mueve", sostiene la presentación (32).

Desde estos aparatos represivos del Estado provincial pueden advertirse ejecuciones y concreciones de decisiones políticas que dan cuenta de una "derechización" y un endurecimiento respecto de los modelos de control desplegados especialmente en relación a la población pobre, vulnerabilizada, joven de la provincia. Es así al punto que:

el ex ministro de Seguridad bonaerense y actual asesor de Nilda Garré, León Arslanian, denunció que en la provincia de Buenos Aires hay "niños fuera de todo control social y mano de obra sumamente barata que están haciendo de choferes para los robos de vehículos". En ese sentido, advirtió que la administración de Daniel Scioli carece de la "planificación" necesaria para revertir la situación (33).

Así, este escenario da cuenta de modos de controlar y mantener "en las fronteras de la civilización" a sectores de la población marginalizadas, de pobreza estructural, en general con escasas oportunidades de acceso a la educación y al trabajo formal.

Ahora bien, ¿qué vínculos pueden identificarse entre estas políticas de seguridad en la Provincia de Buenos Aires y las políticas de selección de directores y autoridades para las escuelas secundarias? 


\section{Conclusiones}

Las políticas (entre ellas las educativas) se juegan en campos sociales complejos. Reconocer el papel central que tienen los procesos socio-históricos para comprender los "designios" sobre los sujetos y cómo los imaginarios sociales residuales actúan e inciden en las prácticas de los actores situados, permite no sólo enlazar sujetos e historias sino también entrever los ámbitos de sujeción y de resistencia que desde los propios actores y desde las instituciones pueden sostenerse.

Priorizar en la selección de directores a aquellos que cuenten con un perfil particular: que compartan (supuestamente) imaginarios higienistas y disciplinadores respecto del papel de la educación destinada a determinados sectores de la población a través del control del cuerpo y la acción, daría cuenta de líneas estratégicas en la conducción de la población. Esto aportaría a promover la inclusión de los y las jóvenes a partir de formatos sostenidos mayoritariamente por la contención y el control más que por prácticas centradas en los saberes y la construcción de una ciudadanía participativa y dialógica. Aunque, claramente, en este juego los actores tienen un margen de libertad en sus elecciones. Vale recuperar aquí los aportes que Elías hace respecto de las elecciones que realiza un sujeto o las decisiones que toma en el transcurso de su vida. Elías (1996, citado en Alliaud 2001:129) plantea que estas elecciones superan el plano de lo meramente individual, estando atadas al entramado de dependencias "dentro del cual se abre al individuo un campo de decisiones individuales, que simultáneamente limita sus oportunidades de decisión" (34). Así, como sujetos de la sociedad, a la vez que advierten y deciden, encuentran las opciones limitadas por las racionalidades [35] (Giroux,1992) pregnantes de su tiempo socio-histórico.

Se advierte en la conducción actual -julio de 2012- de la Provincia de Buenos Aires una pretensión de segregación y sometimiento de grupos específicos de la población. Esto se da en un escenario en el que las instituciones -aparatos del Estado- y los actores se constituirían en "gendarmes", custodios de "fronteras".

Tomando como punto de partida la obligatoriedad del Secundario, se reconoce que el nivel debe asumir un desafío impensado en sus orígenes: incluir a grupos sociales históricamente excluidos. Una estrategia que se releva desde la órbita de la gestión central es apelar a ciertos perfiles de directores que estarían en consonancia con esta mirada: la tradicional perspectiva de la educación física asociada al disciplinamiento del cuerpo y de la mente con vistas a un "autogobierno" de la población.

Desde una mirada hacia el pasado, revisando el modo en que se idea y concreta la conformación del sistema educativo en una ciudad de la provincia de Buenos Aires, aunque en principio particular, permite conformar un atisbo sobre una provincia que fue corriendo la línea de frontera y disputando al indio 
sus tierras y la riqueza en diferentes localidades que vivieron procesos similares y permite enlazar con el presente las "fronteras" en las que se disputa el orden, la gobernabilidad actual de la provincia.

En este recorrido se presentaron diferentes elementos del entramado y las líneas que desde el poder ejecutivo conforman y construyen una visión y una prescripción de cómo se espera que se conduzcan los "aparatos de estado". El avance de políticas que avalan y no ponen freno al autogobierno de la policía y la penitenciaria bonaerense tal como muestran los informes y denuncias por parte de organismos nacionales e internacionales de derechos humanos presenta un escenario de horrores y desprecio por la vida.

Desde el mandato de inclusión educativa que prescribe la ley de educación, las escuelas secundarias se ven desbordadas por la dificultad para entablar diálogos y acuerdos con los jóvenes que están más allá de la "frontera": adicciones, violencia, conflictos con la ley, embarazos precoces, "falta de interés" y deserciones.

Retomamos para cerrar a Fernández (1999, p. 5), ya que su alcance y profundidad dejan explícitamente abiertas las deudas pendientes y algunas claves de lectura respecto del papel de la investigación en la intervención social, especialmente en el campo de la educación y del sistema educativo:

El avance de la escuela se hizo sobre la negación de estos desgarramientos. Existió una historia oficial que permitió justificar hechos y aliviar culpas pero no pudo evitar el sobreesfuerzo de crecer soportando en su mismo interior una profunda contradicción.

El saber popular primero, la investigación psicológica y psicosocial después, han dado suficiente evidencia para entender que la resultante de tales situaciones paradojales es una combinación en la que están presentes la parálisis de la acción, la rémora del deseo y la vitalidad -en el mejor de los casos- la insistencia en la rutina y la estereotipia como defensa contra el contacto con una realidad que reinstala la paradoja.

Pensar en procesos de inclusión real no se limita al marco de ley que lo determine y reglamente. Demanda revisar la historia, los imaginarios sociales y los modos en que actores e instituciones entienden e intervienen en la cotidianeidad de las instituciones educativas.

\section{Notas Bibliográficas}

(1) Ley de Educación N² 26.206 del año 2006 y su correlativa ley de la Provincia de Buenos Aires № 13.688/07.

(2) Esto se describe y analiza en múltiples y diversas investigaciones entre ellas: Braslavsky (1985); Willis (1983); Apple (1994), Berstein. (2001); Bourdieu y Passeron (2003); Giroux (2004), entre otros. 
(3) Olavarría cuenta con una localidad cabecera de nombre homónimo, y localidades serranas. Población total del partido: 111.320 habitantes (censo 2010). El coronel Álvaro Barros logró el reconocimiento oficial y decretó la fundación del "Pueblo de Olavarría", el 25 de noviembre de 1867, una ciudad que se conformaba promisoria por lo estratégica en la línea de "frontera con el indio". Con grandes extensiones de cultivo y cría de ganado, se ha destacado desde la década de 1930 por la industria extractiva mineral y sus fábricas cementeras.

(4) Un supuesto que sostiene esta indagación es que, siguiendo a Gravano et al (2005: 3549), la ciudad puede leerse en clave de "palimpsesto urbano". Esta hipótesis da cuenta de las sucesivas imágenes de ciudades que se van superponiendo y quedan como huellas sobre las cuales se inscriben las que las van sucediendo, hasta el presente.

(5) "Más que una oposición binaria entre quienes ejercen el poder y sobre quienes se ejerce, una analítica del gobierno refiere a las estrategias, finalidades, pensamientos y conflictos que, en un momento determinado, definen el núcleo problemático de la conducción y autoconducción de la conducta. Esto es, los modos por los que los seres humanos somos individualizados y direccionados, la variedad de prácticas a través de las cuales se produce el auto-gobierno" (Grinberg, 2007:101).

(6) Gendarme: Agente de Policía, de Francia o de otros países, destinado a mantener el orden y la seguridad pública. Diccionario de la Lengua Española - Real Academia Española. Vigésima segunda edición. http://www.rae.es/rae.html

(7) "El intendente Mendiburu, en su Memoria del año 1910 decía que en esos momentos realizaba trabajos para 'obtener la instalación de una Granja o Escuela práctica de Lechería en el local que ocupó la Gendarmería Volante'. (...) Puede decirse que la Escuela Práctica de Lechería (hoy de Agricultura) empezó a funcionar regularmente el 21 de abril de 1913" (Belfiore, 1947: s/n).

(8) "La gendarmería volante (GV) comienza a funcionar en nuestro país en 1904, (...) una fuerza organizada militarmente. El nuevo organismo tendría sus cuarteles en La Plata, Puán, Olavarría y Avellaneda. Reunían alrededor de 200 personas. (...) En su reglamento consta "...la gendarmería Volante es una fuerza instituida para velar por la seguridad pública. (...) Una vigilancia continua que le permita prevenir antes que reprimir, constituye la esencia de su misión". Comunicación personal. AG, bibliotecaria de la escuela.2011. Agosto 1.

(9) Participan: el gerente del Banco Nación y miembros de la "Sociedad La Edificadora", precursora del que sería "Banco de la Edificadora de Olavarría"; la Sociedad Española; la comisión de Defensa Rural; la Sociedad Rural.

(10) LG es una mujer de unos 60 años cuando se realiza esta entrevista. Estudió magisterio y mientras tenía sus primeros trabajos viaja a Azul para estudiar el profesorado de letras. De familia de clase media, vive en el micro centro. Los fragmentos corresponden a una entrevista realizada en 2006.

(11) A.T es una mujer nacida en Olavarría. Tiene alrededor de 65 años al momento de la entrevista y se ha desempeñado en diferentes ámbitos de gestión en educación: Directora de CIE, Regente de estudios en una escuela privada, Secretaria de Educación de la Municipalidad en el único mandato del PJ desde la vuelta a la democracia y Diputada Provincial (PJ) al momento de la entrevista, cargo que ocupa desde 1999 y dejó en diciembre de 2011.

(12) "Es posible arriesgar como hipótesis (...) que el mandato social es en realidad un doble mandato y como tal encierra una paradoja. En sus aspectos explícitos y públicos se enlaza con una utopía y se expresa en fines y objetivos formales. En sus aspectos ocultos tiene sus raíces en las contradicciones socio-políticas, se vehiculiza a través de 
las condiciones materiales y los modelos de acción y contradice la propuesta utópica. (...) El acto fundacional de un establecimiento educativo parece contener siempre la conjugación de un doble mandato que expresa aspectos generales de la problemática socio-histórica y más profundamente (...) algunas contradicciones que parecen constitutivas de la educación misma" (Fernández et.al, 1999:4/5).

(13) L.R, comunicación personal. Mayo 2012. Se trata de la primera secretaria de la escuela. Actualmente docente en esa escuela, con tareas pasivas. Vecina del barrio de unos 45 años, su madre y ella misma eran parte de la comisión que llevó adelante la gesta fundacional. Ella tenía dos años de recibida cuando accede al cargo, que se lo propone la directora y lo toma.

(14) El Colegio Nacional N² pasa a denominarse Escuela de Educación Media №7 a partir de la ley de transferencia de escuelas y Secundaria $N^{07}$ después de la sanción de la ley 26.206/06.

(15) A.R. es una mujer joven, diseñadora gráfica que retorna de la Ciudad Autónoma de Buenos Aires al egresar de su carrera. Se inicia en la docencia en esta escuela. Es parte de una familia del barrio, madre maestra y padre jubilado de una de las fábricas tradicionales de la ciudad.

(16) "El concepto de ámbito hace referencia a "la amplitud con que se considera el suceso humano que se analiza (Bleger, 1969: 59). (...) El ámbito hace referencia a la extensión, a la amplitud con que se focaliza el fenómeno. Los ámbitos no son excluyentes, por el contrario se complementan en su interjuego. Es fundamental no tomar a uno solo de ellos como si fuera la totalidad, como tampoco confundirlos o superponerlos indiscriminadamente". (Souto, 2000:32). Más adelante la autora señala que "nuestra forma de conceptualizar la relación no es desde contextos delimitados, representables como círculos concéntricos. Se trata de transversalidad y de entrecruzamiento." (Souto, ibídem: 59)

(17) "El concepto de poder se ha sustituido por el de fuerza de juego. (...) fuerza de juego es un concepto de relación. Se refiere a las posibilidades de ganar con que cuenta un jugador en relación con las de otro" (Elías, 1999:88).

(18) "A partir del año 2005, la Dirección General de Cultura y Educación adecuó su Estructura Orgánico - Funcional y, tomando en cuenta la conformación de las 25 Regiones implementadas el año anterior, se dispuso la supresión de las Jefaturas de Inspección Regionales por Rama de Enseñanza y su reemplazo por las Jefaturas Regionales únicas, divididas según se supervise la educación de gestión estatal o de gestión privada; y la creación de una Jefatura por Distrito". www.abc.gov.ar visitado el 02/06/12.

(19) "Estábamos preparados para los que podían acceder al sistema y hoy tienen que estar todos" Diario digital Infoeme, (2011.Noviembre,11) http://www.infoeme.com.ar/noticia. asp?id=46877

(20) "Gramsci define el sentido común de la siguiente forma: "...cada estrato tiene su sentido común que es, en el fondo, la concepción más difundida de la vida y de la moral”, concepción que es "absorbida acríticamente por los diversos ambientes sociales y culturales en que se desarrolla la individualidad moral del hombre medio". De tal modo que, si por un lado cada clase social tiene su propio sentido común por el otro éste es el es la concepción más difundida de la vida y la moral que, en la sociedad desigual, no puede ser otra que la que corresponde a las clases dominantes, es decir, lo que hemos venido denominando visión o discurso hegemónico"(Tamarit, 2002:24. El resaltado es del original).

(21) Esto se advierte en la micropolítica escolar, en los modos en que se hace presente la voz de los estudiantes, la conformación de centros de estudiantes, los acuerdos en la toma de decisiones en la gestión escolar, entre otros. 
(22) "(...) en el sentido que esta palabra fue usada por Foucault: las deliberaciones, las estrategias, las tácticas y los dispositivos utilizados por las autoridades para crear y actuar sobre una población y sus componentes, de modo de asegurar su bien y evitar su mal-, parece como si estuviéramos asistiendo a la emergencia de un rango de racionalidades y de técnicas que tratan de gobernar sin gobernar a la sociedad; gobernar a través de las elecciones reguladas hechas por actores singulares y autónomos, en el contexto de sus compromisos particulares con sus familias y comunidades" (Rose, 1993, 1994 citado en Rose 2007).

(23) Resolución N824. Artículo 80. La Plata, 15/03/05.

(24) "En nuestro país, en la docencia esto varía según el nivel al que se aluda. (...) En el nivel primario y más aún en el inicial, la modalidad del género se imprime al trabajo docente marcado sobre todo por la feminilización desde sus orígenes. En el nivel medio, no nació sino que se hizo una carrera crecientemente de mujeres: en la medida en que se expandió el nivel, se feminilizó y fueron cambiando también algunas características constitutivas del trabajo, «primarizándolo»". Formato de cita electrónica (ISO 690-2) Birgin, Alejandra. Las regulaciones del trabajo de enseñar: Vocación, Estado y Mercado en la configuración de la docencia. 1997 [Citado: 3/9/2012].

(25) Ver en extenso en Aisenstein y Scharagrodsky, et.al 2006.

(26) Edberto Herrera era el responsable de la secretaria de Acción social en la intendencia de Alfieri. Muy vinculado al deporte. Dardo Restivo, otro de los fundadores -responsable con el prof. Barosella de la propuesta curricular-, había sido seminarista antes de ingresar a la formación como profesor de educación física y confeso practicante católico. Recuperado de http://www.aguayaceite.com.ar/verNoticia.php?id=45. Junio 2012.

(27) Esto se continuaba con el desafío de superar pruebas físicas (a veces bochornosas), recordando los históricos rituales de iniciación de los conscriptos o de otras fuerzas de seguridad que se llegan a conocer cuando los incidentes terminan en acciones graves o fatales para los aspirantes. Estas prácticas ya no se organizan desde la institución.

(28) "estereotipos que construimos con nuestras prácticas de amplio espectro y escaso fundamento, estereotipos que alimentamos a cada paso y que nos alejan de los conceptos (...) los estereotipos construidos y avalados por los mismos Profesores de Educación Física con ayuda de sus acciones y de los otros también, nuevamente estereotipos que se fueron adueñando de su propia identidad. (...) Esto nos conduce a un nuevo problema, no nos entendemos como una profesión con dimensión política, la hemos perdido en el camino (Sosa 2007: 23-24).

(29) CELS, "Violencia institucional y políticas de seguridad. Los espacios donde se recicla la violencia policial", en CELS, Informe 2008, ob. cit., p. 91 y ss.; "Regresiones en las políticas de seguridad, una dirección de difícil retorno", en Informe 2009, ob.cit., y “Violencia institucional y políticas de seguridad: refuerzo de las corporaciones y estigmatización de los sectores más vulnerables de la sociedad", en Informe 2010, ob. cit., p. 132 y ss citado en CELS, 2012:145.

(30) Miguel Jorquera Debe haber más celeridad en la Justicia (2012, Junio 1) Página /12. (digital) http://www.pagina12.com.ar/diario/elpais/1-195395-2012-06-01.html

(31) "El vicegobernador Mariotto, defensores oficiales, miembros del CELS y de la CPM recibieron dos facas y una cuchilla que las autoridades de la cárcel de San Martín entregaron a los detenidos para que atacaran a otro. El hecho ocurrió en el proyecto modelo del gobierno provincial. Un sistema perverso, verdadera fábrica de criminalidad y violencia. Terminó la inspección y comenzaron las represalias, con un muerto y un herido. Sólo una decisión política puede cortar con este escándalo reiterado". Horacio Verbitsky Las 
casitas de Casal (2012, Abril 1) Página/12.(digital) http://www.pagina12.com.ar/diario/ elpais/1-190896-2012-04-01.html

(32) Horacio Verbitsky Luz y sombra (2012 Mayo 20) Página/12 (digital). http://www.pagina12. com.ar/diario/elpais/1-194447-2012-05-20.html

(33) Sociedad. Con críticas a Scioli. (2012, Junio 18) Pagina/12 (digital). http://www.pagina12. com.ar/diario/sociedad/3-196624-2012-06-18.html

(34) Elías, N. (1996) La sociedad cortesana Bs As: FCE, citado en Alliaud, A (2001:129). Se hace también referencia allí a otro libro del autor que se dedica a analizar este tema Elías, N. (1998) Mozart, Sociología de un genio. España: Península.

(35) Giroux define a racionalidad como "un conjunto específico de supuestos y prácticas sociales que median las relaciones entre un individuo o grupo con la sociedad amplia. Subyacente a cualquier modo de racionalidad se encuentra un conjunto de intereses que definen y califican cómo los individuos se reflejan en el mundo. Este es un punto epistemológico importante. El conocimiento, expectativas y tendencias que definen una racionalidad condicionan y son condicionados por las expectativas en las que cada uno de nosotros entramos. La noción de que dichas experiencias sólo llegan a ser significativas dentro de un modo de racionalidad que les confiere inteligibilidad es de crucial importancia" (Giroux: 218, 1992). Se hace más clara la importancia de la noción de racionalidad cuando su definición se amplía al concepto de problemática. "Todas las formas de racionalidad contienen una problemática, que es una estructura conceptual que puede ser identificada tanto por los cuestionamientos que plantea como por las preguntas que es incapaz de plantear" (Giroux, 1992:218).

\section{Referencias Bibliograficas}

- $\quad$ Agüero A.; Iglesias, S, del Valle Milanino A. (2009) Enrique Romero Brest y los inicios de la educación física escolar. Su tiempo, su vida, su pensamiento y su obra. Revista eä 1 (1). Recuperado de www.eä-journal.com

- Aisenstein A., y Scharagrodsky, P (2006) Tras las huellas de la Educación Física escolar argentina. Cuerpo, género y pedagogía.1880-1950. Argentina: Prometeo.

- $\quad$ Alliaud, A. (2001). El abordaje del sujeto en la investigación educativa. Retomando los aportes de Norbert Elias. Espacios en Blanco (11), 121-143.

- $\quad$ Althusser, L. (1988) Ideología y aparatos ideológicos de Estado. Freud y Lacan. Argentina: Ediciones Nueva Visión.

- $\quad$ Apple M. (1994) Educación y poder. (2da reimp.). España: Paidós.

- $\quad$ Apple, M. (1996) El conocimiento oficial. España: Paidós.

- Bauman, Z (1999) Consecuencias humanas de la globalización. Argentina: FCE.

- Belfiore N. (coord.) (1947) Album de Olavarría. Homenaje al 80 aniversario de la fundación. 1867 - 1947. Tandil.

- $\quad$ Birgin, A. Las regulaciones del trabajo de enseñar: Vocación, Estado y Mercado en la configuración de la docencia., 1997. [Citado: 3/9/2012] Formato de cita electrónica (ISO 690-2)

- Bleger, J. (1969) Psicología de la conducta. Argentina: Centro Editor de América Latina. Citado en Souto (2000) Las formaciones grupales en la escuela. Argentina: Paidos.

- $\quad$ Calvete, L. y Vales, A. (2011) "Participación Juvenil en la Escuela Secundaria de Sierra Chica durante los años 2009 y 2010. Los Centros de Estudiantes y su posicionamiento en la toma de decisiones". Tesis de Licenciatura en Trabajo Social. FCH. UNICEN. Inédita 
- $\quad$ Carli, S. (2003) Niñez, pedagogía y política. Transformaciones de los discursos acerca de la infancia en la historia de la educación argentina entre 1880 y 1955. (2da ed.) Argentina: Miño y Dávila

- Caruso, M y Dussel, I (1999) La invención del aula. Una genealogía de las formas de enseñar. Argentina: Santillana.

- $\quad$ Centro de Estudios Legales y Sociales (2012) Derechos Humanos en Argentina - Informe 2012. Argentina: Siglo XXI.

- $\quad$ Elias, N. (1999) Sociología fundamental. España: Gedisa.

- Fernández, L. (1994) Instituciones educativas. Dinámicas institucionales en situaciones críticas. Argentina: Paidós.

- $\quad$ Fernández, L. (1999) La historia institucional. Una variable clave en el funcionamiento escolar. FFyL. UBA. Ficha de cátedra. Mimeo.

- $\quad$ Foucault M (1978) Historia de la sexualidad I. España: Siglo XXI.

- $\quad$ Foucault M (2006) Seguridad, territorio, población: Curso en el Collège de France: 19771978. Argentina: Fondo de Cultura Económica.

- $\quad$ Freire, P. (1990). La naturaleza política de la educación. Cultura, poder y liberación. Barcelona: Paidós.

- Giroux H. (1992) Teoría y resistencia en educación España: Siglo XXI editores.

- Gravano, A (Comp.). (2005) Imaginarios sociales de la ciudad media. Emblemas, fragmentaciones y otredades urbanas. Estudios de Antropología urbana Argentina: FACSO. UNICEN.

- Grinberg, S. (2007) Gubernamentalidad: estudios y perspectivas. Revista Argentina de Sociología 5 (8), 95-110.

- Herrera, E. (1992) Memorias...de un protagonista. Ficha de cátedra. ISFD N47. Olavarría. Mimeo.

- Morgade, G. (1992) El determinante de género en el trabajo docente de la escuela primaria. Argentina: Miño y Dávila.

- $\quad$ Rose, $\mathrm{N}$ ¿La muerte de lo social? Re-configuración del territorio de gobierno. En Revista Argentina de Sociología 5 (8),111 a 150.

- Sosa, M. J. (2007) La identidad profesional. Tesina de grado. Universidad Nacional de la Plata - Facultad de Humanidades y Ciencias de la Educación Departamento de Educación Física. Inédita. La Plata, Argentina.

- Souto, M (2000) Las formaciones grupales en la escuela. Argentina: Paidós.

- Tamatit, J. (2002). El sentido común del maestro. Buenos Aires: Miño y Dávila.

- Tamarit, J (1993): Educar al soberano. Crítica al iluminismo pedagógico de ayer y de hoy. Argentina: Miño y Dávila editores.

- $\quad$ Tenti Fanfani, E. (comp.) (2008) Nuevos temas en la agenda de la política educativa. Argentina: Siglo XXI. Unesco. IIPE.

- Umpierrez, A. (2012) Aproximaciones al campo. Enfocar/mirar/analizar/reconstruir/ interpretar. En Anuario de Antropología Social y Cultural en Uruguay, 10 (12), 181-198.

- Umpierrez, A (2009). El acceso a una carrera universitaria de profesorado en una universidad regional: entre elecciones y oportunidades de un campo ocupacional, determinaciones y autonomías, sujetos y contextos. Tesis de Maestría en Educación con Orientación en Ciencias Sociales. FCH. UNICEN. Tandil. Inédita.

- Wacquant, L. (2008). Las Cárceles de la Miseria. Buenos Aires: Ediciones Manantial. 


\section{Otras fuentes:}

Ley de Educación Nacional N²6.206/06

Ley de Educación de la Provincia de Buenos Aires N 13.688/07

http://www.rae.es/rae.html

www.elpopular.com.ar

www.abc.gov.ar

www.infoeme.com.ar

www.spb.gba.gov.ar

www.pagina12.com

http://www.magicasruinas.com.ar/revistero/argentina/fraude-patriotico.htm

http://www.gob.gba.gov.ar/legislacion/legislacion/cye-05-824.html 